\title{
Multicriteria Portfolio Decision Analysis for Project Selection
}

\author{
Alec Morton, Jeff Keisler, Ahti Salo
}

June 24, 2013

\begin{abstract}
Multicriteria Portfolio Analysis spans several methods which typically employ build on MCDA to guide the selection of a subset (i.e., portfolio) of available objects, with the aim of maximising the performance of the resulting portfolio with regard to multiple criteria, subject to the requirement that the selected portfolio does not consume of resources consumed by the portfolio does not exceed the availability of resources and, moreover, satisfies other relevant constraints as well. In this chapter, we present a formal model of this selection problem and describe how this model can present both challenges (e.g. portfolio value may, due to the interactions of elements, depend on project-level decisions in complex and non-additive ways) and opportunities (e.g. triage rules can be used to focus elicitation on projects which are critical) for value assessment. We also survey the application of Portfolio Decision Analysis in several domains, such as allocation of R\&D expenditure, military procurement, prioritisation of healthcare projects, and environment and energy planning, and conclude by outlining possible future research directions.
\end{abstract}

\section{Introduction}

Essentially all organization are faced with the problem of choosing what activities to pursue. This is true of, for example, a high technology or pharmaceutical company, or public sector funder deciding what science to invest in; a Ministry of Defence deciding what equipment to procure; a hospital, insurance fund or health authority deciding what treatments to provide; a local council deciding on what services to provide, and how they are to be spacially distributed; a public authority seeking to distribute a 
budget for the maintenance of infrastructure; an IT department deciding what systems projects to initiate; or an international collaboration deciding what projects to pursue together.

Such problems are often multicriteria or multiobjective. This may be because the organisation's goals are themselves contested and the appropriate balance has to be negotiated between different stakeholders. , it may be because while the organisation has, nominally, a single fundamental objective, such as profitability, the actions on the table are so far removed from this ultimate goal that tracing through the impacts of choices on this goal is not practical, and so decision makers (DMs) rely on assessments of proxies for that goal. Examples of such a situation might be upstream drug development, where detailed market modelling is not possible and so DMs rely on criteria such as unmet need, or allocation of a maintenance budget to roads, where typically the aim is to maintain the road network at a given quality level, rather than to minimise accidents or journey times per se.

These decision problems share a common structure. In all cases, the requirement is to choose a subset of items - a portfolio - from a choice set. This can be contrasted with typical situation in the textbook presentation of multicriteria decision analysis, which we call "single choice", where the DM has to choose a single item (action, option, alternative) from a set (such as a house, car or toaster to purchase). The distinction between portfolio and single choice has a long history and has been described by White [1] as the distinction between explicitly and implicitly defined alternatives, and by Roy [2] as the distinction between the globalised and fragmented concept of an action.

The relationship between these two problems can be conceptualised in various ways. One conceptualisation is to view portfolio choice as a generalisation of the single choice problem: in the single choice problem, the only available portfolios are those containing single items. In this sense, the portfolio choice problem is primary and the single choice problem secondary. From another point of view, the single choice problem is the more fundamental concept: portfolio choice can be seen as a single choice problem, subject to the interpretation that the set from which items are to be selected is a combinatorial set of portfolios. Indeed, some approaches deal with the portfolio nature of choice effectively by restructuring portfolio choice as a single choice problem and by screening the combinatorial set to identify a manageable subset of feasible or attractive portfolios which can then be considered explicitly. The Analysis of Interconnected Decision Areas (AIDA) method [3][4] and the strategy table device [5][6] are examples of this sort of approach. 
The problem of portfolio choice also seems reminiscent of the "sorting problematique" [2][7] where the DM classifies objects as belonging to a member of a set of ordered classes ("excellent", "good", "poor", etc), except that the classification is a binary one, into "accept" and "reject". Sorting differs, however, from portfolio choice in that in sorting there does not have to be a sense in which objects can be joined together or concatenated. Consequently from a sorting point of view, membership of the "accept" or "reject" class is typically determined by whether an object is better or worse than a reference object which lies on the boundary between two classes, rather than by the total cost of the accepted objects, which, from a sorting point of view, is not a meaningful concept.

The problem of portfolio choice can be approached by a common set of approaches. Elsewhere we have called these approaches which seek "to help DMs make informed selections from a discrete set of alternatives through mathematical modeling that accounts for relevant constraints, preferences, and uncertainties", Portfolio Decision Analysis [8]. Although relatively neglected in the academic decision analysis literature (although see [9][10]), Portfolio Decision Analysis accounts for a significant proportion of commercial decision analysis consulting [11]. Moreover, the label "Portfolio Decision Analysis" is a useful blanket term which serves to draw together different formal approaches to the management of portfolios of activity in different domains, underscoring key similarities.

The focus of the current chapter will be on approaches to Portfolio Decision Analysis in which there is explicit recognition of the multicriteria nature of the decision problem: we will call such approaches, Multicriteria Portfolio Decision Analysis or MCPDA. Although our own background is in Multiattribute Value and Utility Theory based methods, we aim, in keeping with the integrative spirit of the volume of which this chapter is a part, to cover and discuss approaches to MCPDA based on a broad range of methods. It should also be noted that many practitioner texts in this area also propose atheoretic scoring methods for project selection, although as this literature is not indexed, a systematic review does not seem possible. Readers are referred to other chapters in the current book for further technical details on the methods referred to.

In this chapter, we have four main aims: firstly, to describe a framework for MCPDA; secondly, to draw attention to key modelling challenges and solutions; thirdly, to review practice in a number of different application domains; and fourthly, to conclude and point the way forward for further research in this area. We devote Sections 2, 3, 4 and 5 to each of these aims respectively. 


\section{A formal framework for MCPDA}

In this section we present a formal framework for MCPDA. The underlying theory of MCPDA is not very well developed and the main relevant reference we are aware of is [12], which the presentation of this chapter follows. However, we use ordinal rather than cardinal independence conditions (as these are easier to state and are more familiar), which give rise to a slightly different representation. We begin our formal development with a model of the portfolio space. It is normally most convenient to consider this space as a subset of $\{0,1\}^{m}$, with the $0-1$ entries representing $m$ binary decisions to do a project or not. Normally that subset will be defined by a constraint set, and normally that subset will include a resource constraint of the form $c(x) \leq B$ which will have an especial significance as will become clear in the next section. In any case, we will denote the portfolio space as $X$, denote a typical member as $x=\left(x_{1}, \ldots, x_{i}, \ldots, x_{m}\right)$ and denote the index set $\{1, \ldots, m\}$ as $M$.

We suppose that there is a vector valued function $g(\cdot)$ which maps each choice of projects into a $m \times n$-dimensional space. The normal interpretation of $g$ is that associated with each decision about each project there is a set of scores which depend on whether a project has been chosen or not: this interpretation requires that $g(x)=\left(g_{1}\left(x_{1}\right), \ldots, g_{m}\left(x_{m}\right)\right)$ where $g_{1}(\cdot), \ldots, g_{m}(\cdot)$ are scoring functions associated with each decision which we will assume in the ensuing. Often in applications, the same scales will be used for all projects, and we will make that assumption here (although see [13] for an example where different scales are used for different types of projects). For example, a scoring system for scientific projects might include scales representing market size, innovativeness, and fit with company mission. We will denote the index set of criteria $N=\{1, \ldots, j, \ldots, n\}$. For a particular project $i$ we will call the space of vectors of project scores $Y^{i}=\prod_{j \in N} Y_{j}$ with typical member as $y^{i}=\left(y_{1}, \ldots, y_{j}, \ldots, y_{n}\right)$. We will call the set of possible vectors of portfolio scores $Y=\prod_{i \in M} Y^{i}$, with typical member as $y=\left(y^{1}, \ldots, y^{i}, \ldots, y^{m}\right)$.

We introduce a preference relation $\succsim_{Y}$ over $Y$. Note that this preference relation is defined not just over possible portfolios of projects as they currently exist, but portfolios of counterfactual projects which do not in fact exist. For example, suppose that project 1 scores five on innovation and seven on strategic fit, and project 2 scores three on innovation and four on strategic fit. A counterfactual version of project 1 scores six on innovation and three on strategic fit. The preference model supposes that I can say 
how I feel about: the actual project 1 by itself, the actual project 2 by itself, the counterfactual project 1 by itself, the actual project 1 together with the actual project 2 , and the counterfactual project 1 together with the actual project 2 .

There are various forms which our preferences over this space might take but following [12], our approach will be to impose certain independence conditions on $\succsim_{Y}$. We shall think of independence in two parts: betweenproject independence and within-project independence. For a given set $I \subset N$ we write $Y^{I}=\prod_{i \in I} Y^{i}$ and $Y^{M / I}=\prod_{i \in M / I} Y^{i}$, denote typical elements $y^{I}$ and $y^{M / I}$ respectively and use the notation $\left(y^{I}, y^{M / I}\right)$ to denote the vector $y$ which has corresponding entries equal to those of $y^{I}$ for all $i \in I$ and $y^{M / I}$ for all $i \in M / I$. Our definition of between-project independence reads as follows.

Definition 1 If a preference ordering $\succsim_{Y}$ has the following property that for some $I \subset M$, for all $\dot{y}_{I}$ and $\ddot{y}_{I} \in Y_{I}$ and $\dot{y}_{M / I} \in Y_{M / I}$

$$
\left(\dot{y}_{I}, \dot{y}_{M / I}\right) \succsim_{Y}\left(\ddot{y}_{I}, \dot{y}_{M / I}\right) \Longrightarrow\left(\dot{y}_{I}, y_{M / I}\right) \succsim_{Y}\left(\ddot{y}_{I}, y_{M / I}\right) \forall y_{M / I} \in Y_{M / I}
$$

then it is said to be between-project independent for $I$ and if this condition holds for all $I \subset M$, it will be said to be between-project independent over $M$.

Subject to suitable auxiliary assumptions (weak ordering, restricted solvability, Archimedeanness and essentiality, as well as technical conditions which may be required in particular cases, for example when $m=2$ or $Z$ has uncountable cardinality), it is well-known that between-project independence over $M$ allows us to write the value functions for portfolios of projects as $u(y)=\sum_{i=1}^{m} u^{i}\left(y^{i}\right)$. However, we also require some way to evaluate the projects. We can do this by defining partial preference orderings $\succsim_{i}$ by $\dot{y} \succsim_{i} \ddot{y}$ iff $\left(\dot{y}^{i}, y^{N /\{i\}}\right) \succsim_{Y}\left(\ddot{y}^{i}, y^{N /\{i\}}\right) \forall y^{N /\{i\}} \in Y^{N /\{i\}}$. As should be evident, the partial preference ordering is represented by $u^{i}\left(y^{i}\right)$.

We now impose another condition on preferences (see [14] and [15] for a use of this principle). To do this, we have to define an indifference relation: say that $\dot{y} \sim_{Y} \ddot{y}$ iff $\dot{y} \succsim_{Y} \ddot{y}$ and $\ddot{y} \succsim_{Y} \dot{y}$. This new assumption is an anonymity assumption: for any permutation $\sigma$ on the set $M,\left(y^{1}, \ldots, y^{m}\right)$ $\sim_{Y}\left(y^{\sigma(1)}, \ldots, y^{\sigma(m)}\right)$. This condition embodies an idea that all that matters in the evaluation of the project is the scores: other attributes (names, sponsors, etc) do not influence preferences. It also follows that each $\succsim_{i}$ can 
be represented the same partial value functions so we can drop the index on $u^{i}(\cdot)$ and write them all as $u^{*}(\cdot)$.

Now for the final move, for a given set $J \subset M$ we write $Y_{J}=\prod_{j \in J} Y_{j}$ and $Y_{M / J}=\prod_{j \in M / J} Y_{j}$, denote typical elements $y_{J}$ and $y_{M / J}$ respectively and use the notation $\left(y_{J}, y_{M / J}\right)$ to denote the vector $y$ which has corresponding entries equal to those of $y_{J}$ for all $j \in J$ and $y_{M / J}$ for all $j \in M / J$. We now define a within-project independence condition:

Definition 2 If a partial preference ordering $\succsim_{i}$ has the following property that for some $J \subset N$, for all $\dot{y}_{J}$ and $\ddot{y}_{J} \in Y_{J}$ and $\dot{y}_{M / J} \in Y_{M / J}$

$$
\left(\dot{y}_{J}, \dot{y}_{M / J}\right) \succsim_{i}\left(\ddot{y}_{J}, \dot{y}_{M / J}\right) \Longrightarrow\left(\dot{y}_{J}, y_{M / J}\right) \succsim_{i}\left(\ddot{y}_{J}, y_{M / J}\right) \forall y_{M / J} \in Y_{M / J}
$$

then it is said to be within-project independent for $J$ and if this condition holds for all $J \subset N$, it will be said to be within-project independent over $N$.

Again, subject to suitable auxiliary conditions, if within-project independence holds, the partial preference ordering $\succsim_{i}$ can be represented by a value function of the form $\sum_{j=1}^{n} u_{j}\left(y_{j}^{i}\right)$. Suppose within-project independence holds for all $i$. We know from the above that $u^{*}(\cdot)$ is also a value function representing the partial preference ordering $\succsim_{i}$ and so there must be a monotonically increasing transformation $\phi: \phi\left(\sum_{j=1}^{n} u_{j}\left(y_{j}^{i}\right)\right)=u^{*}\left(y^{i}\right)$ and hence we have a value function for the portfolio $u(y)=\sum_{i=1}^{m} \phi\left(\sum_{j=1}^{n} u_{j}\left(y_{j}^{i}\right)\right)$. Note that this result (in contrast to that of [12]) does not imply that the value function is additive across both projects and criteria: for example, in the two criteria case, preferences represented by the value function $y_{1}^{1} y_{2}^{1}+y_{1}^{2} y_{2}^{2}$ with the $y_{j}^{i} s$ strictly positive, would respect both the between- and within-project independence axioms. It should also be noted that while if the auxiliary conditions hold at the between-project level there is no guarantee that they will hold at the within-project level (e.g. solvability may hold between projects but fail within projects). Indeed, if independence at the between-project level does not hold, the project-level partial preference ordering will not be complete and so not only can no additive value function exist, but no representation is possible at all. 
A surprising feature of the literature is that other than [12] and [14], essentially no authors seem to have taken on the task of axiomatising MCPDA models specifically. Thus, while the normative theory underpinning multicriteria single choice has grown enormously since the early 1980s, the normative theory of MCPDA has been essentially stagnant. We hope that the remainder of this chapter will make make clear some of the differences between the portfolio choice and single choice paradigm and will suggest to the interested reader possible directions for theoretic development.

\section{$3 \quad$ Modelling challenges}

In this section, we discuss generic issues and process choices in the course of MCPDA modelling. We will organise the section under two headings: structuring the model, and exploring the portfolio space. In order to organise the discussion we will ask you to imagine that you (plus perhaps, families and/ or partners) are confronted with the problem of furnishing a the living room of a new flat, where you will stay for a period of, say 18, months. The size of the budget for furnishing is not clear, but there is a budget of around $£ 500$. Borrowing money is not practically possible and the the items you purchase have no salvage value after your lease runs out.

\subsection{Structuring}

The first stage in OR interventions is that of problem structuring. In the case of an MCDA model, we immediately face a dilemma, as there are two elements to be structured: the criteria and the alternatives (in the portfolio setting, the projects). Which does one do first? [16] has argued persuasively for "value-focussed thinking" - getting clear about values, in quite detailed and operational terms (for example, defining value scales and assessing tradeoffs) before thinking about the construction of alternatives to deliver these values. Thus in our example we might think about what you want to achieve through furnishing the flat (e.g. it is to be a place where you can work, relax, entertain guests, or store excess possessions?). This theme is echoed in the portfolio literature, where value-focussed thinking has been an influential and popular concept: e.g. Bordley [17] cites a situation where R\&D scientists generate low value projects, reflecting "the fact that sometimes a scientist's main input about corporate priorities came from press releases". Nevertheless, there are cases where the projects may simply be given as part of the problem description, and so "alternative-focussed thinking" makes more sense. Examples which come to mind might be the 
allocation of fishing rights to applicants [18], or the choice of locations for army recruitment centres [19].

Without prejudice, we discuss structuring projects first of all. In general, an aim in MCPDA - as in decision analysis in general - is to come up with "creative, doable alternatives" [20]. One downside in encouraging idea generation, however, is that there may be too many alternatives generated to actually assess. A common prescription in the literature is to use some form of shortlisting - for example by using a screening model for a first pass and then more detailed economic or optimisation model to assess consequences in detail [21]. A second approach is to design some way to combine smaller projects into "package projects" (either making use of existing Problem Structuring Methods [22][23] or customised approaches [24]) and assess these packages. In the flat furnishing example, for instance, you might choose to combine a dining table and chairs into a single item, although it would be possible to prioritise the table and chairs separately. This can have several advantages: the numbers of items which have to be evaluated is reduced, saving judgemental effort, packages can be constructed so that they are similar in size, thus avoiding scope insensitivity [10][25] problems at the assessment phase, and it may be possible to construct packages such that the number of interactions between packages is minimised. The drawback is that good projects may be "hidden" within poor packages.

[26] observe that in situations where there may be natural groupings or "areas" for projects, analysts face a choice between establishing the areas first and using those areas to structure idea generation (how might one want to furnish the kitchen? how might one want to furnish the dining room?) on the one hand; and generating projects and then grouping them (as "kitchen projects", "dining room projects", etc), on the other. They observe that this distinction is similar to that between top-down and bottom-up structuring in criteria hierarchies, and between value- and alternative-focussed thinking in the generation of alternatives. This seems plausible: one would expect that these different methods would lead to different option sets (for example if one structures idea generation by asking for possible purchases in either the kitchen or the dining room, DMs may be less likely to generate a coat rack for the hallway which connects the two).

It is common in MCDA approaches to assume that the modelling plays no formal role in generating options. An interesting case where this assumption is relaxed is in the model of Souder and Mandakovic [27][28], who propose a model for coordinating project selection in an organisational setting where subdepartments provide possible projects and the centre acts as DM. They observe that it is possible to think of this problem through 
mathematical programming decomposition, and propose a scheme whereby the centre passes information about preference to subdepartments and subdepartments respond by providing new, improved plans.

A complication which arises in MCPDA, but which is not present in single choice decision analysis applications, is that projects may interact [29][30][31][32]. The standard classification of interactions is into:

- resource actions, where there are savings or additional costs from doing two (or more) projects simultaneously (e.g. it costs less to purchase a dining table and chairs as a set than to purchase them separately);

- technical interactions, where one project cannot be done without first doing another project, or alternatively, doing one project makes doing another impossible (for example, we may have space for the the large refrigerator with icemaker or the smaller one without, but cannot accommodate both); and

- benefit interactions, where doing two (or more) projects together is worth more, or less than the sum of benefits of doing each project individually (we value the wide-screen television more when we have a sofa from which to watch it in comfort).

Modelling these interactions can require considerable ingenuity, e.g. [33][34]. In some cases there may be some underlying model which can be used to define interactions automatically - for example [35] provide a model of road prioritisation in which the road degradation process is explicitly modelled through a Markov chain. In this case a difficulty is that the underlying model has to be incorporated into the PDA model, which may give rise to a problem which is computationally difficult to solve. On the other hand, direct judgemental assessment of interactions is also possible, perhaps through a device such as a cross-impact grid: an obvious drawback of this approach is asking a DM to explicitly assess even just whether an interaction exists and its sign for every pair of projects could represent a substantial judgemental burden. For this reason, [36] advocate deliberately not assessing interactions on the ground that most of them will be not relevant to the decision, and those which are significant can be taken into account outside of the model.

In contrast to the formal model of the last section, some criteria may be at the level of the portfolio rather than at level of the individual project. A common example of such a portfolio-level criterion is "balance" [37][38][39]. Often, it is felt that where there are groupings of projects it is desirable 
that a final allocation be balanced in the sense that there are not "too many" projects of one type or another. This feeling may come from a number of sources. It may, for instance, reflect an urge to diversify for the sake of robustness; on the other hand, it may by underpinned by a principle of "fairness" in resource allocation. Because it is often unclear exactly why balance is desirable, often it goes unmodelled, and is handled informally; alternatively, sometimes balance constraints are implemented within a model, in order to ensure that at least a certain number (or certain monetary value) of projects of a certain type are included in a portfolio [12]. Perhaps the most sophisticated approach to balance is that of [40], who models a concern for balance as a family of separate criteria which minimise deviation from some given distribution of manpower across project categories.

A related portfolio level concern is portfolio risk in situations where project success is probabilistic. In particular, if the success or failure of projects are correlated, it may be desirable to include a project in a portfolio if it is that it is a good hedge against the risk associated with other projects. Seen through this lens, even in a setting where the aim is to maximise wealth, there may be multiple criteria in the sense that one cares both about the expected value and also about the risk. This idea features prominently in the theory of financial portfolios, most notably in the celebrated Markowitz mean-variance model. However, other measures of risk other than the variance are possible, and a rich class of models is available to capture and model this sort of concern [41][42].

\subsection{Exploring}

Once the model elements have been defined, there follows a phase of exploration, where the DM and analyst work together to understand the DMs preferences and how they relate to the set of possible portfolios. The precise nature of this exploration will depend on the multicriteria method used. In the Multi-Attribute Value Theory modelling framework, for example, the analyst would take the DM through specific valuation and weighting questions designed construct partial value functions and aggregate them into a common value measure. Once this has been done, the problem has been effectively reduced to a single objective value maximisation problem - although of course one may want to go back to elicited weights and values subsequently in a sensitivity analysis phase. On the other hand, in a multiobjective programming setting, exploration may involve the generation of all non-dominated portfolios. 
We do not intend in this section to describe the various MCDA methods which might be applied to the problem of portfolio choice, although this is a popular area of application and so it is probably true to say that every significant MCDA method has been applied to portfolio choice at some time or another (see the literature review in the following section). However, we do outline and comment on a few salient and generic ideas which seem to be popular and which can be used within the context of any MCDA method.

A first popular idea is that of bubble charts [43][44][32]. These methods are predominantly used in the context of models where there are at least two dimensions of value and a single cost dimension. The idea in these charts is to present the possible projects in the bicriteria space, representing a particular project by a circle, the size of which reflects the investment cost associated with the project - see Figure 1 for a possible bubble chart for the flat furnishing example, with the various possible purchases scored on two dimensions, comfort and aesthetics. These displays seem to be found useful by DMs as a way of understanding more deeply the available alternatives. However, the displays themselves embed significant assumptions, most notably that there is a single criterion score associated with a project, which may not be the case if there are interaction or balance constraints.

A second popular idea is that of triage. This idea exploits the observation that even if one has incomplete information about the DM's preferences, it may be possible to "decide" a subset of projects. Projects which are contained in all members of the the set of portfolios which are optimal with respect to some value function compatible with preference information expressed by the DM, can be decide positively; those which contained in no members of that set of portfolios can be decided negatively. Thus, with even limited, incomplete information about preference, it should be possible to narrow the space of investigation and concentrate attention on a small number of critical projects where analysis can really make a difference. This idea has been investigated in simulation studies by [45] (see also [46]) and forms the basis of the RPM-Decisions software described in [47][48]. In Figure 2, we show an example of the core index display from the RPM software for the flat furnishing problem. With no information about weights, it is not possible to say definitively what the optimal portfolio is, as there are two possibilities: however, both possible optimal portfolios contain the first and second bookshelves, the radio, the pot plant and the coffee table; neither of them contain the television; and the DVD player, dining table and sofa are each contained in one and one only of the two.

Another way to explore the portfolio space is to use a cost-benefit display of the type built into the Equity [36] and PROBE [49] software, which is 


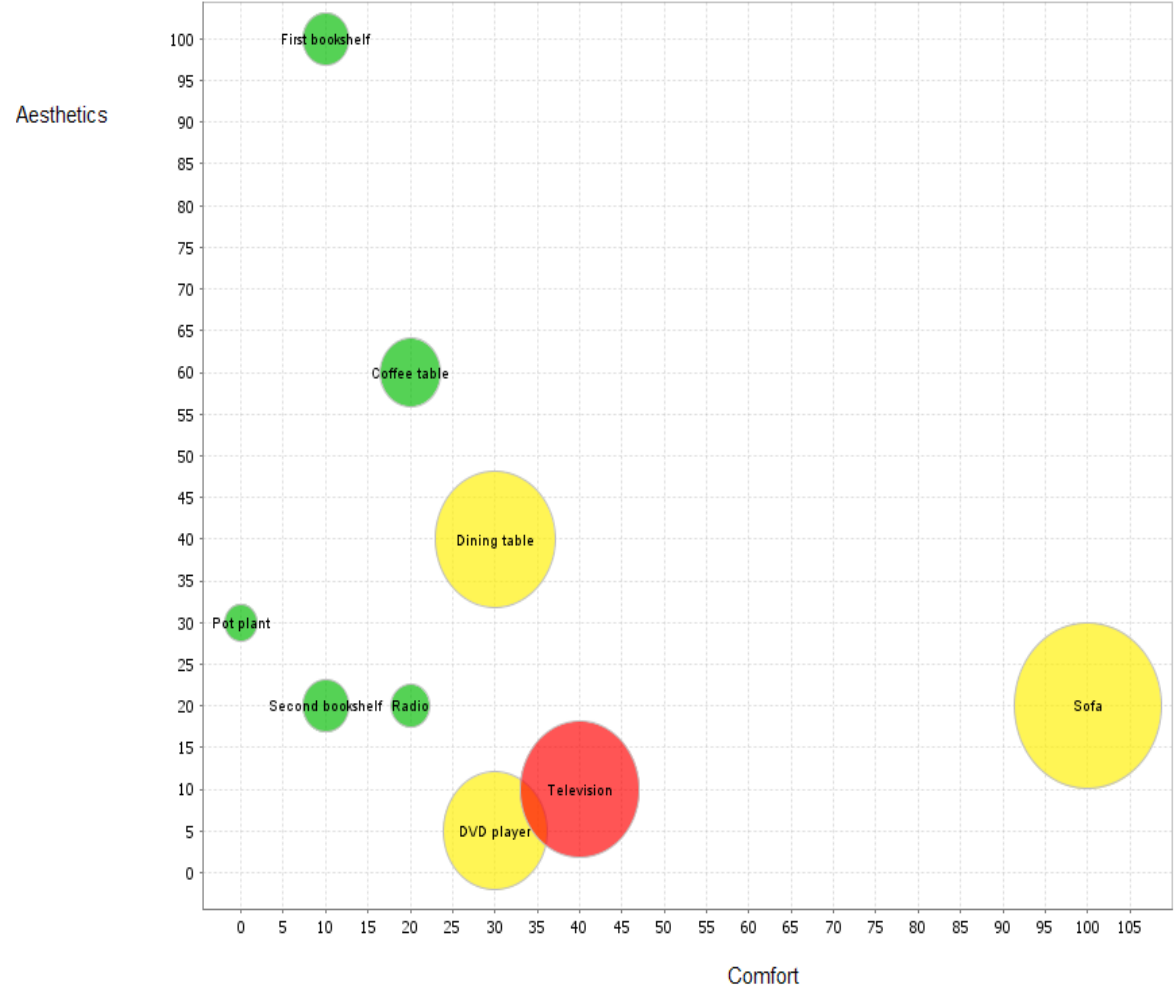

Figure 1: Bubble chart for the flat furnishing example 


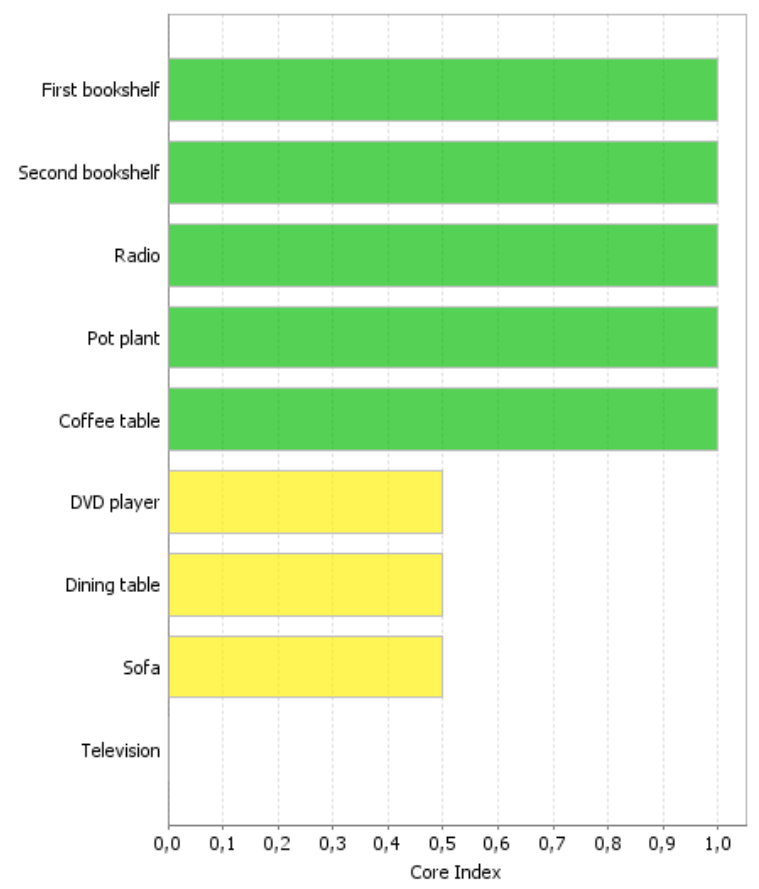

Figure 2: Core index display for the flat furnishing example 


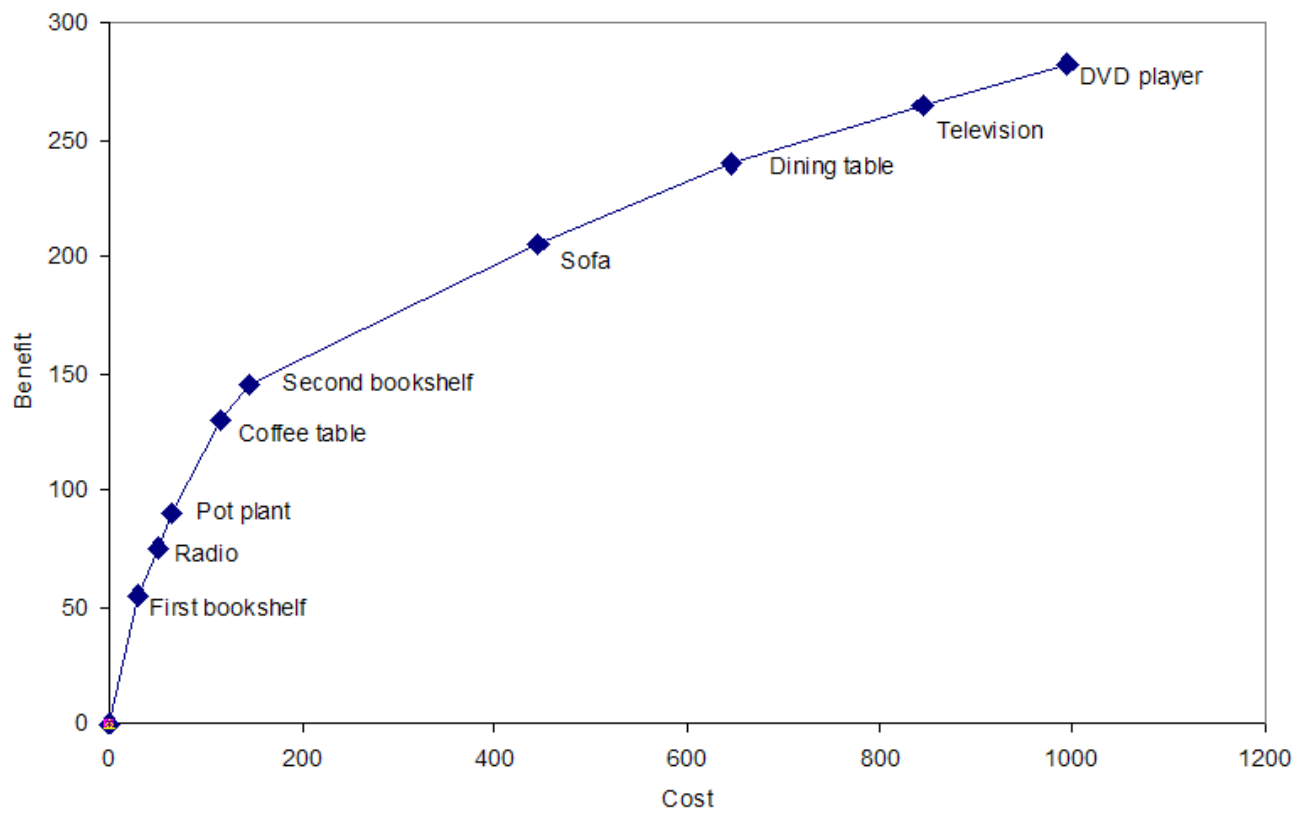

Figure 3: Pareto front display for the flat furnishing example

applicable where there is single dimensional budget constraint $c(x) \leq B$, and cardinally measurable values have been assessed. From a mathematical standpoint, this display can be viewed as the Pareto front of a bicriterion problem which chooses non-dominated portfolios which maximise value and minimise cost; from a practical point of view it has the interpretation as the cumulative value obtained from implementing the optimal portfolio at some given level of spend, with linear interpolations between the discrete levels. In the simplest case, where criterion and value functions are linear, value increments associated with projects are unique and well-defined and the display can be generated by dividing benefit by cost for each project and proceeding down the resulting ranking, cumulating benefit and cost [9]. In more complicated environments, it may be necessary to solve a sequence of optimisation problems to generate this display. The Pareto front display for the flat furnishing example is shown in Figure 3, assuming that the aesthetics and comfort scores can be combined with equal weights. 


\section{Application domains}

In this section, we study four application domains: Research and Development (R\&D) project selection; military planning and procurement; commissioning health services; and environment and energy planning. These application domains are not exhaustive. Nevertheless, they give a good general idea of the sorts of problems to which MCPDA has been applied, and the sorts of methods which have been used.

\subsection{R\&D project selection}

Technical innovation is one of the engines of growth for both firms and nations in advanced economies. However, undertaking Research and Development $(\mathrm{R} \& \mathrm{D})$ to support innovation is expensive and outcomes are hard to forecast, sometimes even hard to characterise. It should therefore come as no surprise that the OR community has been extremely active in developing solutions for $R \& D$ prioritisation. Indeed $R \& D$ management is easily the preeminent application area for portfolio and project selection models, and over several decades a vast literature dealing with this problem has accumulated (reviewed in [50][51][52][53][43][54][38]). Some of these models are mono-criterion in nature, typically in private sector settings where money provides a natural objective. Such models typically focus on the modelling of technical and production uncertainties about project delivery and market uncertainties about a project's ability to generate revenues.

However, importantly for this chapter, there are several multicriteria models which have been proposed. It is important to realise that the term $R \& D$ covers a large number of different activities, and that the reasons for advocating multicriteria methods may be quite different depending on the purpose and context of the R\&D in question. For example, in a government-sponsored programme of fundamental science, projects may have quite different outcomes (e.g. a Science and Engineering research council may fund projects which contribute to energy, healthcare, environmental improvement, transport...), and so (even if benefits could be accurately projected) there may be no single natural metric of value on which to compare projects. Further, the government sponsors of such a programme may have policy objectives, such as sponsoring interdisciplinarity, which reflect a philosophical view of the nature of the innovation process, rather than relating to specific benefits. Private sector R\&D managers who have a nominal single financial objective, on the other hand, may be so far from the delivery to the customer that this objective does not meaningfully guide operational 
choices. This could be because the projects to be considered are in the very early phases of development and detailed market modelling is not possible, or it could be because projects are instrumental in nature, and are intended to contribute to, for example, internal operational objectives rather than generating revenues.

The literature on $R \& D$ prioritisation - even multicriteria $R \& D$ prioritisation - is vast and practically impossible to review completely. The simplest form of multicriteria approach is the scoring model [55][56][57][58][59][60][61], where projects are scored on a number of different dimensions using some form of attribute scale, then scores are weighted and combined, either additively or using some more complicated formula, to give an overall metric of value. Such models go back decades - for example as far back 1957, Rubinstein [62] discusses criteria for the evaluation and control of R\&D projects, as well as then-current practice. However, despite (or perhaps more accurately, because of) their simplicity, scoring approaches are very much alive today [43]. While such models are likely to be useful as a tool for structuring reflection relative to holistic judgement, they are often developed and applied in apparent ignorance of the most basic decision analysis principles. As a result, it is very unclear what assumptions are being made about preferences and what the numbers (e.g. criteria weights) DMs are expected to provide mean. Such models may therefore produce a number which may guide decision making - but without DMs being forced to think as clearly as they could have been.

However, the use of multicriteria models is by no means limited to scoring models. Since the 1970s, practically all major multicriteria approaches have at some time between applied in connection with R\&D prioritisation: indeed, typically a few years after a new multicriteria approach has been proposed it surfaces in the R\&D project and portfolio selection context.

Considering first what one might think of as decision analysis or related methodologies, the early 80s were notable for several prominent applications using the then-new Multiattribute Utility Theory (MAUT) [12][13], although certain scoring models proposed earlier do show awareness of decision theoretic principles and so might be considered proto-decision analyses [57][58]. Of related interest are the applications of [63][64] which seek to support resource allocation using a MAUT frame - although these do not constitute portfolio selection models, as utility functions are assessed directly on levels of investment with no intervening concept of a discrete project as a vehicle by which money is transformed into value. From the mid-1980s one starts to see the Analytic Hierarchy Process (AHP) and subsequently the Analytic Network Process (ANP) emerge as a competitor to 
MAUT [65][66][67] and a popular extension seems to be to combine the AHP with fuzzy numbers [68][69]. Of particular interest in this area is the work by [70] which uses both MAUT and AHP, and seeks to compare both approaches; also [71] describes an application of a technique called the Judgmental Analysis System (JAS), but like the AHP uses pairwise comparison data, but finds scores using geometric least squares rather than eigenvalue decomposition. Outranking approaches have been less prominently applied in this domain, but examples of applications using outranking principles do exist [51][72], and it should also be noted that R\&D prioritisation is a prominent running example in the book of Roy [2] which is the central text on outranking methods.

A difficulty with the use of decision analysis methods in the domain of R\&D project prioritisation - and indeed of prioritisation generally - is that one has to capture the possibility of selecting more than one project and that projects may interact, at least through their consumption of a shared resource. A simple and popular way to model this shared resource consumption is to divide value scores by money for a "bang for the buck" index [36][43]. A variant on this idea is to use some sort of efficiency analysis approach such as DEA [72][73][74], but careless use of DEA methods can be misleading for the reasons laid out in [75]. An alternative way to deal with shared resource consumption is to take the outputs from a MAUT or AHP model, and use these as coefficients in an optimisation model e.g [12][65], in which the shared resource limit is modelled as a constraint. This has the advantage that other interactions can be modelled in the same framework. However, significant ingenuity may be required to incorporate the the nonlinear value functions which arise from the decision analysis modelling into an optimisation model [76][77]. Using value scores within the context of an optimisation model seems a peculiar thing to do, however, partly for technical reasons - it is not clear whether solutions to the optimisation problem will be invariant with respect to permissible transformations of the utility scale [78] - but also because, since the decision recommendation will be based on a mono-criterion model, there is no natural way for the decision maker to comtemplate the impact of value uncertainty on his decision.

In the light of the difficulty of articulating how the decision analysis part of the problem relates to the underlying optimisation problem, it should come as no surprise, therefore, that contemporaneously and to some extent in parallel, researchers have explored the application of various multiobjective optimisation based approaches in the $\mathrm{R} \& \mathrm{D}$ prioritisation context. Initially, one sees enthusiasm for (weighted) goal programming [79][80][81][82], and latterly for exotic versions of goal programming, such as the stochastic 
version proposed in [83]. In one of the very few papers which bridges the divide between decision analysis and optimisation methods, [77] explore preemptive goal programming, compromise programming, and a minsum model which minimises the weighted sum of attribute distances from an ideal point. [84] question the use of goal programming and advocate instead exact multiobjective optimisation methods, but they use a multiobjective linear programming framework which does not capture project indivisibility. [85] do capture indivisibilities, but the researchers restrict themselves to finding the supported efficient solutions of a rather small bicriteria problem. In general, modelling indivisible projects in an optimisation framework, raises difficulties with the combinatorial explosion in the number of efficient solutions. This can be dealt with through interactive methods [40][86]; through the use of multiobjective metaheuristics [87][88], or through some combination of both [89]. The flexibility of the metaheuristic approach can be seen in [90] where a multicriteria combined portfolio selection and manpower planning model is studied and solved, and in [91] which deals with a stochastic bicriteria version of the same problem. Moreover, recently the RPM approach [47], which blends decision analysis and optimisation methods and concepts, has been deployed in the $\mathrm{R} \& \mathrm{D} /$ innovation context, both at the level of prioritisation of specific projects [92], as well as at the level of prioritisation of research themes or topics [93][94].

As noted above, the R\&D prioritisation literature cannot be faulted for the absence of advanced analytic methods. However, a theme which recurs in the R\&D prioritisation literature is - despite several detailed and published applications of implemented systems - that the advanced methods proposed in the literature are not finding widespread application in field settings [95][96][97]. The available empirical evidence on this point is rather out of date, and it could be that recent developments in organisational data and IT systems render these concerns obsolete. Nevertheless, if one believes such concerns have validity, a common prescription is that analytic methods should either be less technically complex (at least insofar as technical complexity imposes judgemental demands on DMs), and that there should be a renewed focus on the processual aspects of providing decision support, the institutional context of analysis, and the factors which drive successful institutionalisation [36][98].

\subsection{Military planning and procurement}

Military planning and procurement decisions have been an important application area for MCPDA, in the light of the strategic importance of these 
decisions, the difficulty in characterising benefits, and the large sums of money involved. For this discussion, we draw heavily from the work of [99]. They describe and reference many military portfolio decision analyses, and note the following distinguishing characteristics as compared with other portfolio decisions: Legal constraints on the decisions and the decision process; strong political players; hostile adversaries; and complex systems. In addition, military portfolios involve non-financial resources and therefore may have multiple resource constraints. Furthermore, it may require considerable effort to define objectives that in essence make tradeoffs for unknown decision makers in hypothetical situations such as future battle conditions. Identifying and weighing the objectives in military portfolios is often a matter of discovery because they involve scenarios that have not occurred.

[99] identify military portfolio problems involving decisions about: "system acquisition, logistics, personnel management, training, maintenance, communications" and "weapon systems, types of forces, installations". Other portfolios in the literature involve forces, land use, infrastructure (e.g.[100]), system elements, arms transfers [101], and capabilities [102][103]. Military portfolios may be defined in terms of assets to be procured or deployed, and portfolio elements may be distinguished in terms of location, asset type, and function.

[99] describe cases where stakeholders with different significant power bases have strong and sometimes conflicting preferences which makes the construction of value functions challenging. An extreme example might be one in which resources must be allocated across Navy, Army and Air Force assets, with senior leaders from each branch differing in their views of what is most important. Even within a single military service, there may be widely divergent views about the correct way forward: [104] describes how decision conferencing was used to develop value models for different stakeholders and to explore the implications of these value models for decisions about assets to be included in a major naval craft design.

Nevertheless, although stakeholders and their advisors may differ in their view of what drives value, unity of command means that there is one fundamental objective (force preparedness for national defence and the fulfilment of international obligations). However, because views about the best way to achieve this objective differ, and more importantly, because the military (at least in liberal democracies) is subject to strong political oversight, effective MCPDA processes have to include sensitivity analysis of results to assumptions about weights, and processes that are transparent and allow for clear explanation of the rationale behind recommendations. 
Many of the objectives are derived from mission objectives, which are typically defined in formal documents and require operationalisation to a level where they can be applied to guide choice between particular types of equipment. Additional objectives include cost, safety, environmental impact, public acceptance (particularly in the case where decisions involve the use of specific sites for military purposes) and, higher level objectives than those of the mission, e.g., international relations [105].

Methods used for value modeling in military MCPDA include MultiAttribute Value and Utility theory, often within a Value-Focussed Thinking [106] framework; in some cases, the large scale of national efforts means that it is reasonable to assume that values are essentially linear, while in other cases, e.g., readiness of a particular unit, utility can easily be non-linear in some attributes - once force is overwhelming, there is limited additional benefit in investing further resources. [107] describe an approach to the selection of portfolios of weapons systems in a context where the underlying performances are generated by a combat simulator. The Analytic Hierarchy Process has also been used, e.g., for project selection [108]. When military portfolio decisions are meant to build preparedness for complex futures, scenario-based methods are often used [109][110]. Some analyses are largely about determining project-level value measures for ranking and prioritisation of investments. However, many of the primary operations research methods originated in military applications, and so it is not surprising that other problems involve sophisticated mathematical optimisation, in settings where a very large number of decisions must be coordinated, e.g., personnel manpower assignment [111][112], within a structured, stable and well-understood system, e.g. [113].

\subsection{Commissioning health services}

Broadly speaking, healthcare provision in developed countries takes one of two forms. Either healthcare is provided by insurance companies (e.g. Germany, the Netherlands), or it is provided by government, and funded out of general taxation (e.g. the UK, Italy, Canada). In both cases, there are opportunities for multicriteria analysis to help with the policy process (see [114] for two case studies of SMART to assist with health policy agendasetting in the Netherlands), but in the latter case there is a particularly acute need as delivery organisations are effectively instruments of government, but their mandates are not articulated at a level of detail adequate to guide concrete choices about investment. It is on this latter case that we focus on in this section. 
In order to provide support decision making in publicly funded healthcare systems, various multicriteria portfolio methods have been developed and proposed. Generally these proponents of these methods are reacting to a health economic orthodoxy in which prioritisation in health is considered to be a more-or-less a technical exercise in maximising health, with health measured through Quality-Adjusted Life Years or QALY [115][116]. (A QALY is essentially a measure of time-integrated quality of life.) While the sophistication which has gone into refining these health metrics is considerable health state measurement and valuation has become a small industry - for some, they miss the point. For one thing, for local decision makers, who are tasked with comparing alternative investments, building a full-blown health economic model may simply not be practical, and so multicriteria methods offer the opportunity to bring a greater degree of order to the prioritisation process without excessive cost [117]. For another, insofar as healthcare prioritisation depends critically on judgement, it has to involve deliberation by decision makers and dialogue with key stakeholders [118][114]. As key value judgements are either hidden within the construction of the QALY, or ignored, the QALY is inadequate as a guide to priority setting, and hence the need for multicriteria methods.

As in the R\&D management setting, many organisations have independently developed scoring rules which meet the need to provide some sort of orderly approach to prioritisation but which cannot be located in any particular theoretic tradition. As these scoring rules tend to be documented, if at all, in the grey literature and in non-peer reviewed publications, locating them can be quite challenging. Fortunately, [119] and [117] review some of these approaches, going back to the last century (and [117] also provide a model which has been used by the Argyll and Clyde Health Board in Scotland). More recently, however, there has been a greater interest in formal multicriteria approaches, particularly in the Program Budgeting and Marginal Analysis (PBMA) community. PBMA (e.g. [120][121][122]) is a structured approach to decision making about investment and disinvestment in healthcare, which involves identifying current patterns of resource use (program budgeting), and then identifying opportunities for investment and disinvestment (marginal analysis). Despite apparent success, indeed even popularity (a 2001 review [123] identified 78 applications of PBMA in 59 organisations), PBMA does not incorporate in its original form a formalised (or indeed even explicit) benefit metric, although some studies have used multiple criteria in an atheoretic way [124]. Recognising this limitation, [125] in Canada and [126][127] and colleagues in England have conducted applications in the PBMA tradition but which also draw explicitly on MCDA 
literature (specifically the Multi-Attribute Value and Utility traditions) - for example in [125] a formal swing weighting approach was used. [128][129] also describe case studies of a method for prioritisation which draws heavily on the decision conferencing approach of [36], which seems to be the first instance of a MCPA method, formally identified as such, being used in this setting. In a separate development, a team of researcher/ practitioners associated with the World Health Organisation have also become become advocates for multicriteria methods [130]. In their approach, policy makers are presented with pairs of multiattributed healthcare interventions and attribute weights are derived by fitting a logistic regression model. Case studies of this approach in Ghana and Nepal are presented in [131][132][133].

In terms of the methods used in this area, it should be noted that (certainly compared to R\&D management and military) the methods seem to be relatively simple. The focus tends to be on valuing projects rather than valuing the portfolio as a whole ([128][129] are exceptions). Although, there seems to be an emerging consensus that dividing value scores by costs and thus generating an efficiency ranking makes sense in an environment where one is concerned about resource use [134], the methods which are used to generate the value scores are predominantly single choice methods, which can give rise to misleading conclusions [135][15]. There is no formal attention given to inter-project interdependencies, although there may well be interdependencies at the cost, benefit and value levels, or to balance concerns, for example between different diseases or subpopulations.

\subsection{Environment and energy planning}

In environmental planning and in energy planning (in which environmental considerations loom large, e.g.[136]), MCPDA has a natural place. MCDA is relevant because there are often non-financial impacts of importance to society in general and to different stakeholder groups, as demonstrated by the wealth of applications [137][138][139][140][141]. PDA is relevant in the environmental context because impacts of decisions have impact across numerous distinct portions of a larger ecosystem; and in energy because discrete units necessarily combine to form a larger energy delivery system.

There is such a variety of environmental applications (see [142]) that we do not aim here for any kind of comprehensive review. We instead give a flavor of the applications of MCPDA in this context, the commonly used attributes and resources as well as the range of stakeholders as they relate to these different portfolios, and the methods used and type of results generated. 
Energy-related portfolio decisions most often involve discrete physical assets or types of assets to acquire, develop or deploy. These include: Acquisition of generation assets in a fleet or region, e.g., a mix of nuclear plants, coal plants, and wind turbines [143]; selection of generation sources for a particular user, e.g., a self-sufficient energy supply for a military installation [144]; selection of sources of a particular type such as hydropower [145] and technology investments as discussed elsewhere in Subsection 4.1. These are typically business decisions taken within regulatory constraints, or government funding decisions primarily (though not exclusively) viewed through an economic lens. Energy policy may also involve a set of decisions involving non-economic considerations, e.g. [146].

A common approach to project selection is to use MCDA to value essentially independent projects, while the portfolio aspect involves allocating funds across the projects. Applications include technology development or acquisition portfolios within for a single area (e.g., Solar energy, [12]) or across areas of renewable energy technologies [147] or other types of green technologies, e.g, [109]. Likewise, sets of possible remediation efforts [148] can treated as project portfolios. Another related problem is site selection, e.g., selecting a number of sites for the disposal or storage of industrial [149] or even nuclear [150] waste.

Some environmental portfolios have a spatial aspect. Land use problems (e.g., [151]), can be formulated as a portfolio of activities (uses) to which a set of regions (resources) is assigned; alternatively, the regions themselves can be the portfolio and their value can be a function of their dispositions (as suggested in [152]). Similarly, a region may contain a portfolio of habitats [153], ecosystems [154][155] or species [156][157] to be protected. Because areas on a map can be divided in arbitrarily many ways, environmental impacts of actions and policy can be viewed evaluated in terms of their effects on arrays of sub-regions, although such problems are not usually formulated explicitly as portfolio valuation or optimisation. Water management actions may also be considered at a portfolio level, with interactions between elements due to hydrology [158]. When geography is a constraint on portfolio formation, geographic information systems (GIS) are commonly used, and efforts to combine MCDA and GIS have been quite successful [159] in facilitating the decision process and valuing alternatives. An challenge for use of GIS in portfolio decisions is the incorporation of mathematical optimisation methods [160] with clearly defined decision variables that connect with the rich GIS representation of a situation.

Other applications involve management of environmental and resources, e.g., mining and agriculture [161][162]. A sophisticated example of this class 
is described in [163] that considers a portfolio of forest areas to be planted, allowed to grow, and finally harvested.

Other portfolios are organized by levers controlled by different types of decision makers. Sets of laws and regulations can be treated as a portfolio, e.g., the fuel-economy portfolio [164]. Because laws are hard to describe as mathematical decision variables within a well-defined space, optimisation methods are difficult to apply, but evaluating a given set of portfolio alternatives using MCDA is practical. Business decision makers often consider portfolios of business units [165], portfolios of products [166], and portfolios of product design specifications [167]. These decision classes have been considered in the environmental context in some cases using project selection methods (e.g., choosing a point from the efficient frontier) along with MCDA, while in other cases using MCDA tools such as the balanced scorecard to evaluate alternative strategies [168].

In environmental MCPDA, there are many possible stakeholders [169]: nation states have an interest in levels of pollution; the whole of humanity (of today and of the future) and the natural ecosystem have a stake in whether there is global climate change. Communities have an interest in the local environmental effects, both positive and negative of both industrial development and environmental remediation and protection; a special case of this is when the local residents are indigenous peoples and the activities are introduced by outside players. Regulators, governments and governmental organisations may represent these interests in their role as public representatives or bring interests of their own. Environmental groups may have concerns about particular ecosystems, species, regions or habitats, while individuals may be concerned about health, recreation, and even property values. Businesses have an interest in pursuing activities with economic benefits, as well as maintaining those benefits that arise from healthy environments (e.g., fishing), as well as in limiting the costs of compliance with environmental regulation. Energy portfolios involve similar sets of stakeholders, e.g., energy producers, energy consumers, and society at large.

In some cases, the criteria used in environmental decision models are hierarchical and first divided into health/safety, economic value, and ecological considerations, and then into more detailed considerations, e.g., types of emissions [170]. Criteria used in MCPDA for environmental applications tend to be similar to those used in non-portfolio MCDA. An exception is equity/fairness which naturally arises as a concern when a number of separate entities are affected, e.g.[171].

Energy criteria include cost and profit, of course, and also capacity, quality of power, local footprint and pollution from both generation (particularly 
CO2) and from obtaining fuel. Risk is often an issue (e.g. [172][173]); in energy, some of the aggregate risk may be considered in a similar manner to that of financial portfolios (e.g., mean-variance models [174]). In environmental portfolios, outcomes of concern are mostly downsides to be avoided, either degradation or disaster, and cumulative risk and impact may be of concern.

Methods used in environmental problems tend to be quite participative. GIS tools, mentioned above, are prominent because of their usefulness in visualisation and their ability to make issues clear to varied audiences. Other stakeholder sensitive methods, e.g., PROMETHEE (for example as in [175]), and iterative methods, e.g., MCRID [176], are common in facilitating a decision process, while MAUT has also been used in studies supporting government bodies (e.g. [177]). While in energy portfolios, optimisation is common, in environmental portfolios, analysis is used either for simpler prioritisation and ranking, or for evaluation of a set of alternative strategies.

\section{Conclusion and directions for future research}

In this chapter we have outlined what we see as some key themes in the use of multicriteria methods for the selection of portfolios of discrete projects. In Section 2, we presented a formal framework for MCPDA, based on the contribution of [12]. In Section 3 we have described some of the main modelling challenges and opportunities which arise in applying multicriteria methods in the context of portfolio and project selection. In Section 4, we contextualised the discussion by surveying particular application domains.

We will conclude this chapter by discussing what we see as possible directions for future research, which draws on material we have presented in the introductory chapter of our book [178], and to which we refer the reader for more details. Our guiding philosophy is that as the selection of project portfolios is intrinsically a strategic issue, attention to technical modelling must go hand in hand with attention to social process. We group our discussion under three headings: extending MCPDA theory, methods and tools; expanding the MCPDA knowledge base; and embedding MCPDA in organizational decision making, which roughly echo the themes of Sections 2,3 , and 4 respectively.

- Extending MCPDA theory, methods and tools. As well as being a fruitful area for applications, MCPDA also offers a rich field for theoretic development. As we tried to lay out in Section 2, the funda- 
mental axiomatics of which underlie MCPDA remains underdeveloped. Moreover, the design of software tools and algorithms also raises theoretic challenges. Insofar as the implied optimisation model underlying MCPDA is a knapsack problem, it is computationally hard in the deepest sense, and in the multicriteria environment, this is compounded by the difficulty of specifying completely the objective function. Moreover, in an environment where much of the analysis happens "on the fly" in workshops or in meetings with clients, algorithmic speed may be of critical importance. Therefore, there is a real role for mathematical and computational development in the mainstream of the OR tradition to support the advancement of MCPDA.

- Expanding the MCPDA knowledge base. In section 3 we discussed the process of modelling in MCPDA, outlining some of the tools which have been proposed and found widespread use. Yet understanding of how best to structure and manage decision processes requires drawing on knowledge beyond the boundaries of what might be traditionally thought of as OR. One of the most obvious linkages is to behavioural decision theory, which is profoundly relevant to questions of how best to elicit preference judgements and display information. And insofar as MCPDA is intended to support planning processes, many of the other organisational sciences (such as organisational development) have much to offer in terms of helping design better ways to structure and organise decision workshops.

- Embedding MCPDA in organizational decision making. One of the key lessons from Section 4, which dealt with application domains, is the extent to which practice varies and to which organisational context and sectoral matters. Indeed, contextualisation and customisation of MCPDA methods to particular settings can give rise to interesting modelling challenges: for example, some approaches to MCPDA may be purposely designed to reflect the information flows and hierarchical structure of the client organisation; others may reflect data limitations and preferred cognitive styles and professional backgrounds of individuals in a particular industry. Hence, the development of usable MCPDA tools can itself be seen as research into the characteristic features of portfolio decisions in a variety of different contexts.

Acknowledgement 3 Thanks to Eeva Vilkkumaa and Juuso Liesiö for their help in generating Figures 1 and 2. 


\section{References}

[1] D. J. White, Decision Methodology: a formalisation of the OR process, Wiley, London, 1975.

[2] B. Roy, Méthodologie multicritère d'aide á la décision, Economica, Paris, 1985.

[3] J. Friend and A. Hickling, Planning Under Pressure: The Strategic Choice Approach, Pergamon, Oxford, 2nd ed., 1997.

[4] J. K. Friend and W. N. Jessop, Local Government and Strategic Choice: An Operational research approach to the processes of public planning, Tavistock, London, 1969.

[5] R. A. Howard, "Decision analysis: practice and promise," Management Science 34(6), pp. 679-695, 1988.

[6] C. T. Spradlin and Kutoloski, "Action-oriented portfolio management," Research - Technology Management 42(2), pp. 26-32, 1999.

[7] C. Zopounidis and M. Doumpos, "Multicriteria classification and sorting methods: A literature review," European Journal of Operational Research 138(2), pp. 229-246, 2002.

[8] A. Salo, J. Keisler, and A. Morton, eds., Portfolio decision analysis: methods for improved resource allocation, Springer, New York, 2011.

[9] C. W. Kirkwood, Strategic decision making: multiobjective decision analysis with spreadsheets, Duxbury, Belmont, 1997.

[10] D. N. Kleinmuntz, "Resource allocation decisions," in Advances in decision analysis, W. Edwards, R. F. Miles, and D. von Winterfeldt, eds., pp. 400-418, CUP, Cambridge, 2007.

[11] D. N. Kleinmuntz, "Foreword," in Advances in Portfolio Decision Analysis: Improved Methods for Resource Allocation, A. Salo, J. Keisler, and A. Morton, eds., Springer, New York, 2011.

[12] K. Golabi, C. W. Kirkwood, and A. Sicherman, "Selecting a portfolio of solar energy projects using multiattribute preference theory," Management Science 27, pp. 174-189, 1981. 
[13] K. Golabi, "Selecting a portfolio of nonhomogeneous R and D proposals," European Journal of Operational Research 21(3), pp. 347-357, 1985 .

[14] J. Liesiö, "Measurable multiattribute value functions for project portfolio selection and resource allocation. unpublished manuscript," tech. rep., Systems Analysis Laboratory, Aalto University, 2010.

[15] A. Morton, "On the choice of baselines in portfolio decision analysis. LSEOR 10.128," tech. rep., Management Science Group, Department of Management, London School of Economics, 2010.

[16] R. L. Keeney, Value focused thinking: a path to creative decisionmaking, Harvard University Press, Cambridge, 1992.

[17] R. F. Bordley, "R\&D project selection versus R\&D project generation," Ieee Transactions on Engineering Management 45(4), 1998.

[18] T. J. Stewart, A. Joubert, and R. Janssen, "MCDA framework for fishing rights allocation in South Africa," Group Decision and Negotiation 19(3), pp. 247-265, 2010.

[19] C. Bana e Costa and J. Thomaz, "Locating centres of information and recruitment of volunteers for the Portugese armed forces: A decision analysis case study," 2000.

[20] D. Matheson and J. Matheson, The Smart Organisation: creating value through strategic REBD, Harvard Business School Press, Boston, 1998.

[21] J. F. Bard, R. Balachandra, and P. E. Kaufmann, "An interactive approach to R-and-D project selection and termination," IEEE Transactions on Engineering Management 35(3), pp. 139-146, 1988.

[22] C. Bana e Costa, M. L. da Costa-Lobo, I. A. Ramos, and J.-C. Vansnick, "Multicriteria approach for strategic planning: the case of barcelos," in Aiding decisions with multiple criteria: essays in honour of Bernard Roy, D. Bouyssou, E. Jacquet-Lagreze, P. Perny, R. Slowinsky, D. Vanderpooten, and P. Vincke, eds., Kluwer, 2002.

[23] G. Montibeller and L. A. Franco, "Resource allocation in local government with facilitated portfolio decision analysis," in Portfolio Decision Analysis: methods for improved resource allocation, A. Salo, J. Keisler, and A. Morton, eds., Springer, New York, 2011. 
[24] C. A. Bana e Costa and R. C. Oliveira, "Assigning priorities for maintenance, repair and refurbishment in managing a municipal housing stock," European Journal of Operational Research 138, pp. 380-391, 2002 .

[25] A. Morton and B. Fasolo, "Behavioural decision theory for multicriteria decision analysis: a guided tour," Journal of the Operational Research Society 60(2), pp. 268-275, 2009.

[26] G. Montibeller, L. A. Franco, E. Lord, and A. Iglesias, "Structuring resource allocation decisions: A framework for building multi-criteria portfolio models with area-grouped options," European Journal of Operational Research 199(3), pp. 846-856, 2009.

[27] T. Mandakovic and W. E. Souder, "A flexible hierarchical model for project selection and budget allocation," $R \&$ D Management 15(1), pp. 23-29, 1985. Aax01Times Cited:4Cited References Count:24.

[28] T. Mandakovic and W. E. Souder, "An interactive decomposable heuristic for project selection," Management Science 31(10), pp. 12571271, 1985. Ast48Times Cited:19Cited References Count:47.

[29] G. E. Fox, N. R. Baker, and J. L. Bryant, "Economic-models for Rand-D project selection in the presence of project interactions," Management Science 30(7), pp. 890-902, 1984. Tb126Times Cited:49Cited References Count:26.

[30] P. Fahrni and M. Spatig, "An application-oriented guide to researchand-development project selection and evaluation methods," $R \& D$ Management 20(2), pp. 155-171, 1990.

[31] R. L. Schmidt, "A model for R\&D project selection with combined benefit, outcome and resource interactions," IEEE Transactions on Engineering Management 40(4), pp. 403-410, 1993.

[32] G. E. Blau, J. F. Pekny, V. A. Varma, and P. R. Bunch, "Managing a portfolio of interdependent new product candidates in the pharmaceutical industry," Journal of Product Innovation Management 21(4), pp. 227-245, 2004.

[33] Y. Grushka-Cockayne and B. De Reyck, "Towards a single european sky," Interfaces 39(5), pp. 400-414, 2009. Grushka-Cockayne, Yael De Reyck, Bert. 
[34] Y. Grushka-Cockayne, B. De Reyck, and Z. Degraeve, "An integrated decision-making approach for improving european air traffic management," Management Science 54(8), pp. 1395-1409, 2008.

[35] P. Mild and A. Salo, "Combining a multiattribute value function with an optimization model: An application to dynamic resource allocation for infrastructure maintenance," Decision analysis 6(3), pp. 139-152, 2009. Mild, Pekka Salo, Ahti.

[36] L. D. Phillips and C. Bana e Costa, "Transparent prioritisation, budgeting and resource allocation with multi-criteria decision analysis and decision conferencing," Annals of Operations Research 154(1), pp. 5168, 2007.

[37] P. H. Farquhar and V. R. Rao, "A balance model of revaluating subsets of multiattributed items," Management Science 22(5), pp. 528-539, 1976.

[38] C. F. Chien, "A portfolio-evaluation framework for selecting R\&D projects," $R$ \& D Management 32(4), pp. 359-368, 2002.

[39] C.-F. Chien and F. Sainfort, "Evaluating the desirability of meals: An illustrative multiattribute decision analysis procedure to assess portfolios with interdependent items," Journal of Multi-Criteria Decision Analysis 7, pp. 230-238, 1998.

[40] T. J. Stewart, "A multicriteria decision support system for R-and-D project selection," Journal of the Operational Research Society 42(1), pp. 17-26, 1991.

[41] J. Gustafsson and A. Salo, "Contingent portfolio programming for the management of risky projects," Operations Research 53(6), pp. 946956, 2005.

[42] J. Gustafsson, B. De Reyck, Z. Degraeve, and A. Salo, "Valuation of risky projects and other illiquid investments using portfolio selection models," in Portfolio Decision Analysis: methods for improved resource allocation, A. Salo, J. Keisler, and A. Morton, eds., Springer, New York, 2011.

[43] R. G. Cooper, S. J. Edgett, and E. J. Kleinschmidt, Portfolio Management for New Products. 2nd edition., Basic Books, New York, 2001. 
[44] J. Kloeber, "Current and cutting edge methods of portfolio decision analysis in pharmaceutical R\&D," in Portfolio Decision Analysis: methods for improved resource allocation, A. Salo, J. Keisler, and A. Morton, eds., Springer, New York, 2011.

[45] J. Keisler, "Value of information in portfolio decision analysis," Decision Analysis 1(3), pp. 177-189, 2004.

[46] J. Keisler, "The value of assessing weights in multi-criteria portfolio decision analysis," Journal of Multi-Criteria Decision Analysis 15, pp. 111-123, 2009.

[47] J. Liesiö, P. Mild, and A. Salo, "Preference programming for robust portfolio modeling and project selection," European Journal of Operational Research 181(3), pp. 1488-1505, 2007.

[48] a. M. P. Liesiö, J and A. Salo, "Robust portfolio modeling with incomplete cost information and project interdependencies," European Journal of Operational Research 190(3), pp. 679-695, 2008.

[49] B. e. C. C. Lourenço, J C and A. Morton, PROBE - A multicriteria decision support system for portfolio robustness evaluation. Revised version., LSE Operational Research Group Working paper number LSEOR 09.108. London, LSE., 2009.

[50] W. E. Souder and T. Mandakovic, "Research-and-development project selection models," Research Management 29(4), pp. 36-42, 1986.

[51] N. Danila, "Strategic evaluation and selection of R \& D projects," $R$ \& D Management 19(1), pp. 47-62, 1989.

[52] R. L. Schmidt and J. R. Freeland, "Recent progress in modeling R\&D project-selection processes," IEEE Transactions on Engineering Management 39(2), pp. 189-201, 1992.

[53] J. Martino, $R$ \& D project selection, Wiley, Chichester, 1995.

[54] K. Heidenberger and C. Stummer, "Research and development project selection and resource allocation: A review of quantitative modelling approaches," International Journal of Management Reviews 1(2), pp. 197-224, 1999.

[55] B. V. Dean and M. J. Nishry, "Scoring and profitability models for evaluating and selecting research projects," Operations Research 13(4), pp. 550-569, 1965. 
[56] J. R. Moore and N. R. Baker, "Computational analysis of scoring models for R and D project selection," Management Science 16(4), pp. B212-232, 1969.

[57] D. H. Gustafson, G. K. Pai, and G. C. Kramer, "A "weighted aggregate" approach to R \& D project selection," AIIE Transactions $\mathbf{3}(1)$, pp. 22-31, 1972.

[58] D. Cardus, M. J. Fuhrer, A. W. Martin, and R. M. Thrall, "Use of benefit-cost-analysis in the peer-review of proposed research," Management Science 28(4), 1982.

[59] D. Costello, "A practical approach to R-and-D project selection," Technological Forecasting and Social Change 23(4), pp. 353-368, 1983.

[60] A. D. Henriksen and A. J. Traynor, "A practical R \& D projectselection scoring tool," IEEE Transactions on Engineering Management 46(2), pp. 158-170, 1999.

[61] W. R. Bitman and N. Sharif, "A conceptual framework for ranking R\&D projects," Ieee Transactions on Engineering Management 55(2), pp. 267-278, 2008.

[62] A. H. Rubinstein, "Selecting criteria for R and D," Harvard Business Review 35(1), pp. 95-104, 1957.

[63] D. L. Keefer, "Allocation planning for R \& D with uncertainty and multiple objectives," IEEE Transactions on Engineering Management EM-25(1), pp. 8-14, 1978.

[64] D. L. Keefer and C. W. Kirkwood, "A multiobjective decision analysis: budget planning for product engineering," Journal of the Operational Research Society 29(5), pp. 435-442, 1978.

[65] M. J. Liberatore, "An extension of the Analytic Hierarchy Process for industrial research-and-development project selection and resourceallocation," IEEE Transactions on Engineering Management 34(1), pp. $12-18,1987$.

[66] D. L. Thurston and Y. Q. Tian, "Integration of the analytic hierarchy process and integer programming with linear constraints for long range production planning," Mathematical and Computer Modelling 17(4), pp. 41-53, 1993. 
[67] L. M. Meade and A. Presley, "R\&D project selection using the Analytic Networkwork Process," IEEE Transactions on Engineering Management 49(1), 2002.

[68] Y.-G. Hsu, W.-H. Tzeng, and J. Z. Shyu, "Fuzzy multiple criteria selection of government-sponsored frontier technology projects," $R \mathscr{E} D$ Management 33(5), pp. 539-551, 2003.

[69] C. C. Huang, P. Y. Chu, and Y. H. Chiang, "A fuzzy AHP application in government-sponsored R\&D project selection," OmegaInternational Journal of Management Science 36(6), pp. 1038-1052, 2008.

[70] G. Lockett and M. Stratford, "Ranking of research projects - experiments with 2 methods," Omega-International Journal of Management Science 15(5), pp. 395-400, 1987.

[71] P. Naudé, G. Lockett, and K. Holmes, "A case study of strategic engineering decision making using judgmental modeling and psychological profiling," IEEE Transactions on Engineering Management 44(3), pp. 237-247, 1997.

[72] M. Oral, O. Kettani, and P. Lang, "A methodology for collective evaluation and selection of industrial research-and-development projects," Management Science 37(7), pp. 871-885, 1991.

[73] J. D. Linton, S. T. Walsh, and J. Morabito, "Analysis, ranking and selection of $\mathrm{R} \& \mathrm{D}$ projects in a portfolio," $R \& \mathcal{E}$ D Management $\mathbf{3 2}(2)$, pp. 139-148, 2002.

[74] S. Jayanthi, E. C. Witt, and V. Singh, "Evaluation of potential of innovations: A DEA-based application to us photovoltaic industry," IEEE Transactions on Engineering Management 56(3), pp. 478-493, 2009.

[75] D. Bouyssou, "Using DEA as a tool for MCDM: some remarks," Journal of the Operational Research Society 50(9), pp. 974-978, 1999.

[76] A. Mehrez and Z. Sinuany-stern, "Resource-allocation to interrelated risky projects using a multiattribute utility function," Management Science 29(4), pp. 430-439, 1983. 
[77] G. R. Madey and B. V. Dean, "Strategic planning in R\&D using decision analysis and mathematical programming," IEEE Transactions on Engineering Management EM-32(2), pp. 84-90, 1985.

[78] F. S. Roberts, "Meaningfulness of conclusions from combinatorial optimization," Discrete Applied Mathematics 29, pp. 221-241, 1990.

[79] A. J. Keown, B. W. Taylor, and C. P. Duncan, "Allocation of research and development funds - zero-one goal programming approach," Omega-International Journal of Management Science 7(4), pp. 345351, 1979.

[80] J. M. Mellichamp, W. L. Dixon, and S. L. Mitchell, "Ballisticmissile defense technology management with goal programming," Interfaces 10(5), pp. 68-74, 1980.

[81] B. W. Taylor, L. J. Moore, and E. R. Clayton, "R-and-D project selection and manpower allocation with integer non-linear goal programming," Management Science 28(10), pp. 1149-1158, 1982.

[82] R. Khorramshahgol and Y. Gousty, "Delphic Goal Programming (DGP) - a multiobjective cost-benefit approach to research-anddevelopment portfolio analysis," IEEE Transactions on Engineering Management 33(3), pp. 172-175, 1986.

[83] J. F. Bard, "Using multicriteria methods in the early stages of new product development," Journal of the Operational Research Society 41(8), pp. 755-766, 1990.

[84] J. L. Ringuest and S. B. Graves, "The linear multi-objective R-and-D project selection problem," IEEE Transactions on Engineering Management 36(1), pp. 54-57, 1989.

[85] A. F. Czajkowski and S. Jones, "Selecting interrelated research-anddevelopment projects in space technology planning," IEEE Transactions on Engineering Management 33(1), pp. 17-24, 1986.

[86] M. Henig and H. Katz, "R and D project selection: a decision process approach," Journal of Multi-Criteria Decision Analysis 5, pp. 169171, 1996.

[87] K. Doerner, W. J. Gutjahr, R. F. Hartl, C. Strauss, and C. Stummer, "Pareto ant colony optimization: A metaheuristic approach to multi- 
objective portfolio selection," Annals of Operations Research 131(1-4), pp. 79-99, 2004.

[88] A. F. Carazo, T. Gomez, J. Molina, A. G. Hernandez-Diaz, F. M. Guerrero, and R. Caballero, "Solving a comprehensive model for multiobjective project portfolio selection," Computers \& Operations Research 37(4), pp. 630-639, 2010.

[89] C. Stummer and K. Heidenberger, "Interactive R\&D portfolio analysis with project interdependencies and time profiles of multiple objectives," IEEE Transactions on Engineering Management 50(2), pp. 175-183, 2003.

[90] W. J. Gutjahr, S. Katzensteiner, P. Reiter, C. Stummer, and M. Denk, "Multi-objective decision analysis for competence-oriented project portfolio selection," European Journal of Operational Research 205(3), pp. 670-679, 2010.

[91] W. J. Gutjahr and P. Reiter, "Bi-objective project portfolio selection and staff assignment under uncertainty," Optimization 59(3), pp. 417$445,2010$.

[92] M. Lindstedt, J. Liesiö, and A. Salo, "Participatory development of a strategic product portfolio in a telecommunication company," International Journal of Technology Management 42(3), pp. 250-266, 2008.

[93] V. Brummer, T. Konnola, and A. Salo, "Foresight within ERA-NETs: Experiences from the preparation of an international research program," Technological Forecasting and Social Change 75(4), pp. 483495, 2008.

[94] E. Vilkkumaa, A. Salo, and J. Liesiö, "Multicriteria portfolio modeling for the development of shared action agendas," Group Decision and Negotiation, forthcoming.

[95] M. J. Liberatore and G. J. Titus, "The practice of management science in R-and-D project-management," Management Science 29(8), pp. 962-974, 1983. Rd525Times Cited:78Cited References Count:32.

[96] R. L. Schmidt and J. R. Freeland, "Recent progress in modeling R\&D project-selection processes," IEEE Transactions on Engineering Management 39(2), pp. 189-201, 1992. 
[97] S. A. Shane and K. T. Ulrich, "Technological innovation, product development, and entrepreneurship in management science," Management Science 50(2), pp. 133-144, 2004.

[98] A. Morton, D. Bird, A. Jones, and M. White, "Decision conferencing for science prioritisation in the uk public sector: a dual case study," Journal of the Operational Research Society 62, pp. 50-59, 2011.

[99] R. C. Burk and G. S. Parnell, "Portfolio decision analysis: lessons from military applications," in Portfolio Decision Analysis: methods for improved resource allocation, A. Salo, J. Keisler, and A. Morton, eds., Springer, New York, 2011.

[100] D. Buckshaw, G. Parnell, W. Unkenholz, D. Parks, J. Wallner, and O. Saydjari, "Mission oriented risk and design analysis of critical information systems," MILITARY OPERATIONS RESEARCHALEXANDRIA- 10(2), p. 19, 2005.

[101] R. Sherwin and E. Laurance, "Arms transfers and military capability: Measuring and evaluating conventional arms transfers," International Studies Quarterly 23(3), pp. 360-389, 1979.

[102] P. K. David, S. R. D, and B. J, Portfolio Analysis methods for assessing capability options, Rand Corporation, 2008.

[103] I. Linkov, F. Satterstrom, and G. Fenton, "Prioritization of capability gaps for joint small arms program using multi-criteria decision analysis," Journal of Multi-Criteria Decision Analysis 16(5-6), pp. 179-185, 2009 .

[104] L. D. Phillips, "The royal navy's type 45 story: a case study," in Portfolio Decision Analysis: improved methods for resource allocation, A. Salo, J. Keisler, and A. Morton, eds., Springer, New York, 2011.

[105] N. Gass, "Conflict analysis in the politico-military environment of a new world order," The Journal of the Operational Research Society 45(2), pp. 133-142, 1994.

[106] R. L. Keeney, Value focused thinking: a path to creative decisionmaking, Harvard University Press, Cambridge, 1992.

[107] J. Kangaspunta, J. Liesiö, and A. Salo, "Cost-efficiency analysis of weapon system portfolios," European Journal of Operational Research 223(1), pp. 264-275, 2012. 
[108] M. Greiner, J. Fowler, D. Shunk, W. Carlyle, and R. McNutt, "A hybrid approach using the analytic hierarchy process and integer programming to screen weapon systems projects," Engineering Management, IEEE Transactions on 50(2), pp. 192-203, 2003.

[109] J. Jackson, J. Kloeber Jr, B. Ralston, and R. Deckro, "Selecting a portfolio of technologies: An application of decision analysis," Decision Sciences 30(1), pp. 217-238, 1999.

[110] C. Karvetski, J. Lambert, and I. Linkov, "Scenario and multiple criteria decision analysis for energy and environmental security of military and industrial installations," Integrated environmental assessment and management, 2010.

[111] A. Charnes, W. Cooper, and R. Niehaus, "Dynamic multiattribute models for mixed manpower systems," Naval Research Logistics Quarterly 22(2), pp. 205-220, 1975.

[112] D. Klingman and N. Phillips, "Topological and computational aspects of preemptive multicriteria military personnel assignment problems," Management Science 30(11), pp. 1362-1375, 1984.

[113] S. Gass, "Military manpower planning models," Computers $E$ operations research 18(1), pp. 65-73, 1991.

[114] N. Daniels, "Accountability for reasonableness - establishing a fair process for priority setting is easier than agreeing on principles," British Medical Journal 321(7272), pp. 1300-1301, 2000.

[115] K. F. Drummond, M. J. Sculpher, G. W. Torrance, B. J. O' Brien, and G. L. Stoddart, Methods for the Economic Evaluation of Health Care Programmes, OUP, Oxford, 2005.

[116] M. R. Gold, J. E. Siegel, L. B. Russell, and M. C. Weinstein, eds., Cost-effectiveness in health and medicine, OUP, Oxford, 1996.

[117] S. N. Scott and A. Lees, "Developing a prioritisation framework: experiences from a Scottish Health Authority," Health Expectations 4(1), pp. 10-17, 2001.

[118] S. Holm, "Goodbye to the simple solutions: the second phase of priority setting in health care," British Medical Journal 317(7164), pp. 1000-1002, 1998. 
[119] P. M. Mullen, "Quantifying priorities in healthcare: transparency or illusion," Health Services Management Research 17(1), pp. 47-58, 2004.

[120] S. Twaddle and A. Walker, "Program budgeting and marginal analysis - application within programs to assist purchasing in Greater Glasgow Health Board," Health Policy 33(2), pp. 91-105, 1995.

[121] P. Brambleby, "A survivors guide to program budgeting," Health Policy 33(2), pp. 127-145, 1995.

[122] C. R. Mitton and C. Donaldson, "Setting priorities and allocating resources in health regions: lessons from a project evaluating program budgeting and marginal analysis (PBMA)," Health Policy 64, pp. 335348, 2003.

[123] C. Mitton and C. Donaldson, "Twenty-five years of programme budgeting and marginal analysis in the health sector, 1974-1999," Journal of Health Services Research and Policy 6(4), pp. 239-48, 2001.

[124] C. Mitton, S. Patten, H. Waldner, and C. Donaldson, "Priority setting in health authorities: a novel approach to a historical activity," Social Science and Medicine 57, pp. 1653-1663, 2003.

[125] S. J. Peacock, J. Richardson, R. Carter, and D. Edwards, "Priority setting in health care using multi-attribute utility theory and programme budgeting and marginal analysis (PBMA)," Social Science and Medicine 64(4), pp. 897-910, 2007.

[126] E. C. F. Wilson, J. Rees, and R. J. Fordham, "Developing a prioritisation framework in an English Primary Care Trust," Cost effectiveness and resource allocation 4(3), 2006.

[127] E. Wilson, J. Sussex, C. MacLeod, and R. Fordham, "Prioritizing health technologies in a Primary Care Trust," Journal of Health Services Research and Policy 12(2), pp. 80-85, 2007.

[128] M. Airoldi and A. Morton, "Portfolio decision analysis for population health," in Portfolio Decision Analysis: improved methods for resource allocation, A. Salo, J. Keisler, and A. Morton, eds., Springer, New York, 2011.

[129] M. Airoldi, A. Morton, J. Smith, and G. Bevan, Healthcare prioritisation at the local level: a socio-technical approach. SYMPOSE working 
paper no 7., Department of Management, London School of Economics and Political Science, London, 2011.

[130] R. Baltussen and L. Niessen, "Priority setting of health interventions: the need for multicriteria decision analysis," Cost Effectiveness and Resource Allocation 4(14), 2006.

[131] R. Baltussen, E. Stolk, D. Chisholm, and M. Aikins, "Towards a multicriteria approach for priority setting: an application to Ghana," Health Economics 15(7), pp. 689-696, 2006.

[132] R. Baltussen, A. H. A. ten Asbroek, X. Koolman, N. Shrestha, P. Bhattarai, and L. W. Niessen, "Priority setting using multiple criteria: should a lung health programme be implemented in Nepal?," Health Policy and Planning 22(3), pp. 178-185, 2007.

[133] C. Jehu-Appiah, R. Baltussen, C. Acquah, M. Aikins, S. A. d'Almeida, W. K. Bosu, X. Koolman, J. Lauer, D. Osei, and S. Adjei, "Balancing equity and efficiency in health priorities in Ghana: The use of multicriteria decision analysis," Value in Health 11(7), pp. 1081-1087, 2008 .

[134] E. C. F. Wilson, S. J. Peacock, and D. Ruta, "Priority setting in practice: What is the best way to compare costs and benefits?," Health Economics 18(4), pp. 467-478, 2009.

[135] R. T. Clemen and J. E. Smith, "On the choice of baselines in multiattribute portfolio analysis: a cautionary note," Decision Analysis 6(4), pp. 156-262, 2009.

[136] L. Greening and S. Bernow, "Design of coordinated energy and environmental policies: use of multi-criteria decision-making," Energy policy 32(6), pp. 721-735, 2004.

[137] P. Zhou, B. Ang, and K. Poh, "Decision analysis in energy and environmental modeling: An update," Energy 31(14), pp. 2604-2622, 2006.

[138] S. Pohekar and M. Ramachandran, "Application of multi-criteria decision making to sustainable energy planning-a review," Renewable and Sustainable Energy Reviews 8(4), pp. 365-381, 2004. 
[139] M. Bell, B. Hobbs, E. Elliott, H. Ellis, and Z. Robinson, "An evaluation of multicriteria decision-making methods in integrated assessment of climate policy," in Research and practice in multiple criteria decision making: proceedings of the XIVth International Conference on Multiple Criteria Decision Making (MCDM), Charlottesville, Virginia, USA, June 8-12, 1998, p. 228, Springer Verlag, 2000.

[140] A. Balasubramaniam and N. Voulvoulis, "The appropriateness of multicriteria analysis in environmental decision-making problems," Environmental technology 26(9), pp. 951-962, 2005.

[141] J. Huang, K. Poh, and B. Ang, "Decision analysis in energy and environmental modeling," Energy 20(9), pp. 843-855, 1995.

[142] G. Kiker, T. Bridges, A. Varghese, T. Seager, and I. Linkov, "Application of multicriteria decision analysis in environmental decision making," Integrated Environmental Assessment and Management 1(2), pp. 95-108, 2005.

[143] S. Roth, S. Hirschberg, C. Bauer, P. Burgherr, R. Dones, T. Heck, and W. Schenler, "Sustainability of electricity supply technology portfolio," Annals of Nuclear Energy 36(3), pp. 409-416, 2009.

[144] J. Lambert, C. Karvetski, R. Ditmer, T. Abdallah, M. Johnson, and I. Linkov, "Energy security for industrial and military installations: Emergent conditions that influence the strategic selection of technologies," Energy Security , pp. 317-331, 2011.

[145] T. Supriyasilp, K. Pongput, and T. Boonyasirikul, "Hydropower development priority using mcdm method," Energy Policy 37(5), pp. 1866$1875,2009$.

[146] M. Jones, C. Hope, and R. Hughes, "A multi-attribute value model for the study of uk energy policy," The Journal of the Operational Research Society 41(10), pp. 919-929, 1990.

[147] J. Peerenboom, W. Buehring, and T. Joseph, "Selecting a portfolio of environmental programs for a synthetic fuels facility," Operations Research 37(5), pp. 689-699, 1989.

[148] I. Linkov, A. Varghese, S. Jamil, T. Seager, G. Kiker, and T. Bridges, "Multi-criteria decision analysis: a framework for structuring remedial decisions at contaminated sites," Comparative risk assessment and environmental decision making, pp. 15-54, 2005. 
[149] K. Ohman, J. Hettiaratchi, J. Ruwanpura, J. Balakrishnan, and G. Achari, "Development of a landfill model to prioritize design and operating objectives," Environmental Monitoring and Assessment 135(1), pp. 85-97, 2007.

[150] R. Keeney, "An analysis of the portfolio of sites to characterize for selecting a nuclear repository," Risk Analysis 7(2), pp. 195-218, 1987.

[151] M. Christou and M. Mattarelli, "Land-use planning in the vicinity of chemical sites: Risk-informed decision making at a local community level," Journal of hazardous materials 78(1-3), pp. 191-222, 2000.

[152] J. Keisler and R. Sundell, "Combining multi-attribute utility and geographic information for boundary decisions: an application to park planning," Journal of Geographic Information and Decision Analysis 1(2), pp. 101-118, 1997.

[153] T. Svoray, P. Bar Kutiel, and T. Bannet, "Urban land-use allocation in a mediterranean ecotone: Habitat heterogeneity model incorporated in a gis using a multi-criteria mechanism," Landscape and urban planning 72(4), pp. 337-351, 2005.

[154] C. Liu, P. Frazier, L. Kumar, C. Macgregor, and N. Blake, "Catchment-wide wetland assessment and prioritization using the multi-criteria decision-making method topsis," Environmental management 38(2), pp. 316-326, 2006.

[155] T. Randhir and D. Shriver, "Deliberative valuation without prices: A multiattribute prioritization for watershed ecosystem management," Ecological Economics 68(12), pp. 3042-3051, 2009.

[156] M. Drechsler, K. Frank, I. Hanski, R. O'Hara, and C. Wissel, "Ranking metapopulation extinction risk: from patterns in data to conservation management decisions," Ecological Applications 13(4), pp. 990-998, 2003.

[157] A. Moffett, J. Dyer, and S. Sarkar, "Integrating biodiversity representation with multiple criteria in north-central namibia using nondominated alternatives and a modified analytic hierarchy process," Biological conservation 129(2), pp. 181-191, 2006.

[158] E. Chung and K. Lee, "Prioritization of water management for sustainability using hydrologic simulation model and multicriteria decision 
making techniques," Journal of Environmental Management 90(3), pp. 1502-1511, 2009.

[159] J. Malczewski, GIS and multicriteria decision analysis, Wiley, 1999.

[160] X. Li, Y. Chen, X. Liu, D. Li, and J. He, "Concepts, methodologies, and tools of an integrated geographical simulation and optimization system," International Journal of Geographical Information Science $99999(1)$, pp. 1-23, 2010.

[161] G. Mendoza and H. Martins, "Multi-criteria decision analysis in natural resource management: A critical review of methods and new modelling paradigms," Forest Ecology and Management 230(1-3), pp. 1$22,2006$.

[162] S. Mardle, S. Pascoe, M. Tamiz, and D. Jones, "Resource allocation in the north sea demersal fisheries: a goal programming approach," Annals of Operations Research 94(1), pp. 321-342, 2000.

[163] J. Kettunen, Applications of stochastic modelling for investment decision making under market uncertainties. PhD thesis, Helsinki University of Technology, 2009.

[164] T. Berry and M. Jaccard, "The renewable portfolio standard::: design considerations and an implementation survey," Energy Policy 29(4), pp. 263-277, 2001.

[165] A. Ilinitch and S. Schaltegger, "Developing a green business portfolio," Long Range Planning 28(2), pp. 29-38, 1995.

[166] B. Lee and K. Green, "Towards commercial and environmental excellence: a green portfolio matrix," Business Strategy and the Environment 3(3), pp. 1-9, 1994.

[167] G. Olundh and S. Ritzén, "Making an ecodesign choice in project portfolio selection," in Engineering Management Conference, 2004. Proceedings. 2004 IEEE International, 3, pp. 913-917, IEEE, 2004.

[168] W. Tsai, W. Chou, and W. Hsu, "The sustainability balanced scorecard as a framework for selecting socially responsible investment: an effective mcdm model," Journal of the Operational Research Society 60(10), pp. 1396-1410, 2008. 
[169] B. Tonn, M. English, and C. Travis, "A framework for understanding and improving environmental decision making," Journal of Environmental Planning and Management 43(2), pp. 163-183, 2000.

[170] J. Wang, Y. Jing, C. Zhang, and J. Zhao, "Review on multi-criteria decision analysis aid in sustainable energy decision-making," Renewable and Sustainable Energy Reviews 13(9), pp. 2263-2278, 2009.

[171] K. Vaillancourt and J. Waaub, "Equity in international greenhouse gases abatement scenarios: A multicriteria approach," European Journal of Operational Research 153(2), pp. 489-505, 2004.

[172] C. Andrews, "Evaluating risk management strategies in resource planning," Power Systems, IEEE Transactions on 10(1), pp. 420-426, 1995.

[173] E. Hirst and M. Schweitzer, "Electric-utility resource planning and decision-making: The importance of uncertainty," Risk Analysis 10(1), pp. 137-146, 1990.

[174] S. Awerbuch, "Portfolio-based electricity generation planning: policy implications for renewables and energy security," Mitigation and adaptation strategies for Global Change 11(3), pp. 693-710, 2006.

[175] D. Haralambopoulos and H. Polatidis, "Renewable energy projects: structuring a multi-criteria group decision-making framework," Renewable Energy 28(6), pp. 961-973, 2003.

[176] H. Moskowitz, P. Preckel, and A. Yang, "Multiple-criteria robust interactive decision analysis (mcrid) for optimizing public policies," European journal of operational research 56(2), pp. 219-236, 1992.

[177] J. Dyer, T. Edmunds, J. Butler, and J. Jia, "A multiattribute utility analysis of alternatives for the disposition of surplus weapons-grade plutonium," Operations Research 46(6), pp. 749-762, 1998.

[178] A. Salo, J. Keisler, and A. Morton, Portfolio Decision Analysis: improved methods for resource allocation, Springer, New York, 2011. 